\title{
Violações de Direitos Humanos e Justiça de Transição no Brasil Breve cenário quanto à responsabilização penal pelos crimes da ditadura civil-militar
}

\author{
Human Rights Violations and Transitional Justice in Brazil \\ Brief scenario regarding the criminal liability for the crimes of the civil-military dictatorship
}

$\mathrm{E}$

mbora os dez artigos reunidos neste número da revista Sistema Penal \& Violência tratem de temas diversos agrupados entre as duas linhas do programa ${ }^{1}$, é possível identificar um fio condutor entre eles: a prática institucionalizada, sistemática e constante de violações de direitos humanos: violência contra a mulher, o massacre do Carandiru, condições degradantes dos presídios, reformas constitucionais que violam o processo legislativo para abrir a possibilidade de ampliar ainda mais o público alvo dos presídios ao propor a redução da maioridade penal, desprezo por garantias constitucionais e pelo devido processo em nome de um punitivismo violador tanto no Brasil como na Colômbia, o aumento das taxas de homicídio no país, o malogro de propostas de centralização militarizada da segurança pública como se instalou no Brasil durante a Copa do Mundo de 2014, o caráter antidemocrático da mídia brasileira e sua influência no recrudescimento do casuísmo penal. Estes são os temas centrais dos artigos que se apresentam neste número.

Faltou mencionar ainda outro tema desenvolvido neste número e que reservo para maior desenvolvimento neste editorial. O artigo escrito por Gabriel Webber Ziero traz à baila tema que tardou a ser pensado e refletido pela comunidade jurídica brasileira: a responsabilização dos crimes praticados pelos agentes da ditadura civil-militar no Brasil.

Foi desde julho de 2008, quando realizada pela Comissão de Anistia do Ministério da Justiça em pleno Salão Negro do Palácio da Justiça uma audiência pública sobre o questionamento da extensão da anistia para os agentes da ditadura, que o debate conseguiu se fixar tanto na esfera institucional, na midiática quanto na acadêmica. Até então as constantes tentativas de desenvolver o debate empreendidas pelos familiares de mortos e desaparecidos políticos não logravam obter maior repercussão nas esferas mencionadas. Como resultado imediato da audiência pública, além da farta e constante cobertura midiática ${ }^{2}$, houve a propositura de uma Ação de Descumprimento de Preceito Fundamental junto ao Supremo Tribunal Federal. A ação foi proposta pelo Conselho Federal da OAB dois meses após o então Presidente da entidade César Britto ter participado da audiência no Ministério da Justiça.

\footnotetext{
${ }^{1}$ Ao contrário do que fora planejado e divulgado em chamada de artigos na revista Sistema Penal \& Violência, este número não traz um Dossiê sobre o tema "Crise da Democracia de Massas". Apesar da proposta atual e interessante sugerida, não houve a submissão de artigos sobre o tema que lograssem pareceres positivos pelos avaliadores ad hoc da Revista. Por outro lado, foram selecionados sete artigos inéditos na linha de Violência, Crime e Segurança Pública e três artigos inéditos na linha de Sistemas Jurídicos-Penais Contemporâneos.

2 Ver: SILVA FILHO, José Carlos Moreira da. A Comissão de Anistia e a concretização da justiça de transição no Brasil - repercussão na mídia impressa brasileira: jornal O Globo, 2001 a 2010. SILVA FILHO, José Carlos Moreira da; ABRÃO, Paulo; TORELLY, Marcelo D. (orgs). Justiça de Transição nas Américas - olhares interdisciplinares, fundamentos e padrões de efetivação. Belo Horizonte: Fórum, 2013.
} 
À audiência pública seguiu-se no início de 2010 o debate em torno do III Plano Nacional de Direitos Humanos, especialmente em função do Eixo relacionado ao Direito à Memória e à Verdade, que trazia entre outras diretrizes a criação de uma Comissão da Verdade no Brasil. As reações foram imediatas e contundentes, com acusações de parcialidade nessas propostas que beiravam a apologia à ditadura civil-militar. Houve mal estar institucional com as Forças Armadas e pressões pela desqualificação do debate.

Nesse mesmo ano, no final do mês de abril, houve no STF o julgamento da ação que havia sido proposta em 2008 pelo Conselho Federal da OAB, a ADPF 153. Após dois dias de julgamento o resultado foi de sete a dois pelo indeferimento, com votos que trouxeram fundamentos bastante questionáveis, inclusive sob o ponto de vista histórico ${ }^{3}$, chegando-se a afirmar, por exemplo, que na década de 70 a sociedade foi às ruas pedir uma anistia ampla, geral e irrestrita com o sentido de estendê-la aos torturadores do regime de força, quando em verdade o famoso bordão se referia aos presos políticos condenados pela resistência armada, e que, no final, acabaram não sendo mesmo anistiados pela Lei 6.6683/19794.

O julgamento da ADPF 153 no STF foi pautado tão logo se anunciou a data para a audiência da Comissão Interamericana de Direitos Humanos relativa ao Caso Araguaia. A audiência para ouvir o governo brasileiro, foi realizada em Washington apenas um mês após a realização do julgamento do STF, constituindo um dos últimos passos da Comissão para a propositura de ação junto à Corte Interamericana de Direitos Humanos. A manifestação desta viria ainda neste mesmo ano, em novembro, com sentença condenatória ao Estado brasileiro na qual se diz textualmente que

No presente caso, o Tribunal observa que não foi exercido o controle de convencionalidade pelas autoridades jurisdicionais do estado e que, pelo contrário, a decisão do Supremo Tribunal Federal confirmou a validade da interpretação da Lei de Anistia, sem considerar as obrigações internacionais do Brasil derivadas do Direito Internacional $[\ldots] .^{5}$

Do confronto entre as duas decisões revela-se uma situação não pacificada de discordância entre o STF e a Corte IDH quanto ao exercício ou não do necessário controle de convencionalidade pela corte brasileira ${ }^{6}$. O tema segue pendente pela via de Embargos Declaratórios que foram interpostos à decisão na ADPF 153, e

\footnotetext{
3 Para a crítica da decisão do STF e seus fundamentos ver: MEYER, Emilio Peluso Neder. CATTONI, Marcelo. Anistia, história constitucional e direitos humanos: o Brasil entre o Supremo Tribunal Federal e a Corte Interamericana de Direitos Humanos. In CATTONI, Marcelo (org.). Constitucionalismo e História do Direito. Belo Horizonte: Pergamum, 2011, p. 249-288. MEYER, Emilio Peluso Neder. Ditadura e Responsabilização - elementos para uma justiça de transição no Brasil. Belo Horizonte: Arraes, 2012; TORELLY, Marcelo D. Justiça de Transição e Estado Constitucional de Direito - perspectiva teórico-comparativa e análise do caso brasileiro. Belo Horizonte: Fórum, 2012; SILVA FILHO, José Carlos Moreira da. O Julgamento da ADPF 153 pelo Supremo Tribunal Federal e a Inacabada Transição Democrática Brasileira. In: Wilson Ramos Filho. (Org.). Trabalho e Regulação- as lutas sociais e as condições materiais da democracia. Belo Horizonte-MG: Fórum, 2012, v. 1, p. 129-177; SILVA FILHO, José Carlos Moreira da; CASTRO, Ricardo Silveira. Justiça de Transição e Poder Judiciário brasileiro - a barreira da Lei de Anistia para a responsabilização dos crimes da ditadura civil-militar no Brasil. Revista de Estudos Criminais, n. 53, p. 50-87; VENTURA, Deisy. A Interpretação judicial da Lei de Anistia brasileira e o Direito internacional. In: PAYNE, Leigh; ABRÃO, Paulo; TORELLY, Marcelo (orgs.). A Anistia na era da responsabilização: o Brasil em perspectiva internacional e comparada. Brasília: Ministério da Justiça, Comissão de Anistia; Oxford: Oxford University, Latin American Centre, 2011. p. 308-334; PAIXÃO, Cristiano. The protection of rights in the Brazilian transition: amnesty law, violations of human rights and constitutional form (01. September 2014), in forum historiae iuris http://www.forhistiur.de/en/2014-08-paixao/.

${ }^{4}$ Acrescente-se ainda o fato de que nas frequentes assembleias realizadas pelos diversos Comitês Brasileiros pela Anistia (CBA's) as resoluções finais sempre pediam a responsabilização dos crimes da ditadura, conforme anota Heloísa Grecco em sua tese: GRECO, Heloísa Amélia. Dimensões fundacionais da luta pela Anistia. 2009. 456f. [Tese de Doutorado] - Curso de Pós-Graduação das Faculdades de Filosofia e Ciências Humanas da Universidade Federal de Minas Gerais. Belo Horizonte. 2009, e também Carla Rodeghero, Gabriel Dienstmann e Tatiana Trindade: RODEGHERO, Carla Simone; DIENSTMANN, Gabriel; TRINDADE, Tatiana. Anistia ampla, geral e irrestrita: história de uma luta inconclusa. Santa Cruz do Sul: EDUNISC, 2011. p.160-162.

5 CORTE INTERAMERICANA DE DIREITOS HUMANOS. Caso Gomes Lund e Outros ("Guerrilha do Araguaia”) vs. Brasil. Sentença de 24 de novembro de 2010. § 177 Disponível em: <http://www.corteidh.or.cr/docs/casos/articulos/seriec_219_por.pdf>. Acesso em 01 ago. 2015.

6 Sobre a difícil convivência das duas decisões e a própria contradição da corte brasileira em relação à sua jurisprudência anterior ver: SILVA FILHO, José Carlos Moreira da. Justica de Transição - da ditadura civil-militar ao debate justransicional - direito à memória e à verdade e os caminhos da reparação e da anistia no Brasil. Porto Alegre: Livraria do Advogado, 2015. p. 237-260.
} 
que até a data de publicação deste texto ainda não foram pautados. Tornando a polêmica ainda mais incisiva, foi interposta pelo Partido Socialismo e Liberdade (PSOl) outra ADPF, que recebeu o número de ADPF 320, com o mesmo objeto e que obteve em 2014 o parecer favorável do então Procurador Geral da República Rodrigo Janot.

Ainda como efeito direto da condenação do Brasil no caso Gomes Lund, e que ajuda a compreender a mudança de posição da Procuradoria Geral da República sobre o tema, foi o posicionamento do Ministério Público Federal no sentido de propor ações penais para a responsabilização dos crimes da ditadura. No âmbito do MPF, já existia um Grupo de Trabalho em Justiça de Transição, mas que era voz dissidente e minoritária dentro da instituição. Com a condenação do Brasil na Corte Interamericana, o GT foi legitimado e direcionado para criar as condições de cumprimento da sentença no campo da responsabilização criminal, sendo constituído por Portaria da 2 ${ }^{\text {a }}$ Câmara de Coordenação e Revisão em novembro de 2011. Desde então sucessivas denúncias foram formalizadas provocando o judiciário brasileiro a se manifestar ${ }^{7}$. Entre os casos que tem provocado maior repercussão estão o caso Rio Centro e o caso Rubens Paiva. Com exceção honrosa de alguns magistrados, como os juízes federais que trataram das denúncias nos dois casos mencionados acima, o judiciário brasileiro tem se mostrado avesso ao cumprimento da sentença internacional e até mesmo ao debate mais amplo à luz do Direito Internacional dos Direitos Humanos, chegando até mesmo na fundamentação de alguns votos a deixarem escapar manifestações de apologia à ditadura ${ }^{8}$. O destino da maior parte dessas ações tem sido a sua rejeição na segunda instância ou na primeira instância, ou a sua interrupção mediante decisão monocrática de Ministros do STF provocados pelos réus.

Fechando o panorama ainda indefinido sobre a persecução penal dos crimes da ditadura, em dezembro de 2014 foi divulgado o relatório final da Comissão Nacional da Verdade ${ }^{9}$, no qual figura o nome de 377 agentes da ditadura que, de acordo com os esforços de sistematização e investigação da Comissão, praticaram graves violações de direitos humanos e, segundo as recomendações do relatório, devem ser responsabilizados judicialmente.

É neste cenário que se situa a proposta estudada e analisada no artigo de Gabriel Webber Ziero, que trata da possibilidade de julgamento dos crimes de desaparecimento forçado cometidos por agentes da ditadura civilmilitar brasileira perante o Tribunal Penal Internacional. Tal possibilidade se apóia basicamente em duas circunstâncias: o fato de crimes de desaparecimento forçado serem crimes permanentes diante da ausência de vestígios da vítima, e que não suscitariam a prescrição já que continuam a ocorrer enquanto não se revela o paradeiro dos restos mortais, e o fato de que a jurisdição nacional nega-se até o presente a levar adiante a persecução desses crimes, impedindo a análise do mérito seja pelo argumento da prescrição, seja pelo argumento da anistia.

$\mathrm{O}$ artigo explora as diferenças e aproximações entre o enfoque do Direito Internacional dos Direitos Humanos e o do Direito Penal Internacional, buscando dar conta das especificidades relacionadas ao Tratado

\footnotetext{
7 Para um histórico do GT Justica de Transição do MPF, uma síntese das teses adotadas e uma relação de ações penais interpostas ver: BRASIL. MINISTÉRIO PÚBLICO FEDERAL. CÂMARA DE COORDENAÇÃO E REVISÃO, 2. Grupo de trabalho justiça de transição: atividades de persecução penal desenvolvidas pelo Ministério Público Federal: 2011-2013. Brasília: MPF/2a CCR, 2014. Esta publicação foi lançada e divulgada em meio ao Congresso Internacional 50 anos do Golpe e a Nova Agenda da Justiça de Transição no Brasil, ocorrido no mês de março de 2014 em Recife/PE e de cuja organização participaram a Comissão de Anistia e o Grupo de Pesquisa DIreito à Memória e à Verdade e Justica de Transição da PUCRS. Na ocasião, todo o GT Justiça de Transição do MPF esteve presente para publicamente expor à sociedade seu relatório sobre as ações penais e as estratégias adotadas para levá-las adiante. Considero tal fato altamente simbólico e por si só um avanço em termos de aprofundamento da justiça transicional no Brasil.

8 Para a análise de algumas decisões que vem sendo tomadas pelo judiciário brasileiro diante do esforço do MPF ver: SILVA FILHO, José Carlos Moreira da; MEYER, Emilio Peluso Neder; OLIVEIRA, Marcelo Cattoni de; PAIXÃO, Cristiano; TORELLY, Marcelo. Não há anistia para crimes contra a humanidade. Revista Consultor Jurídico, 15/16 set. 2014. A primeira parte está disponível em: <http://www.conjur.com.br/2014-set-15/ nao-anistia-crimes-humanidade-parte>; e a segunda parte está disponível em: <http://www.conjur.com.br/2014-set-16/nao-anistia-crimes-humanidadeparte-ii>. Acesso em 01 ago. 2015.

9 O inteiro teor do relatório está disponível em: <http://www.cnv.gov.br>.
} 
de Roma e à própria jurisprudência do Tribunal e responder ao final da sua análise se é ou não possível que tais crimes sejam ajuizados perante o TPI.

A temática da Justiça de Transição, que vai muito além da responsabilização judicial de crimes contra a humanidade e graves violações de direitos humanos, já foi desenvolvida na revista Sistema Penal \& Violência em edições anteriores ${ }^{10}$, tratando de outros aspectos relacionados às ações institucionais e da sociedade civil organizada para confrontar o passado de violência massiva e de perseguição política, como o reconhecimento e a investigação das violências praticadas, a elaboração e implementação de políticas de memória, a reparação integral individual e coletiva, tanto material quanto simbólica, a reforma das instituições de segurança e das instituições públicas, outrora instrumentalizadas para a prática de violações. O foco não é a punição, mas o esforço para sinalizar em prol da não repetição, a necessidade de reforçar princípios, práticas e estruturas com elevada densidade democrática, e a preocupação em diminuir e evitar a violência estatal.

No que toca ao tema específico da responsabilização criminal, a preocupação de conter a violência do Estado passa por um aspecto estruturante do próprio fenômeno jurídico e que deflagra uma tensão permanente entre o potencial destrutivo e violador do aparato repressivo estatal e a sua função de controle social e correlato emprego da força para a manutenção dos parâmetros isonômicos e legítimos de convivência coletiva. Partindo da compreensão de que o respeito aos direitos dos demais por parte dos cidadãos envolve uma limitação das suas condutas, tem-se o paradoxo de que a liberdade não é possível sem a sua própria limitação ${ }^{11}$. Isto não significa, por certo, a defesa de um modelo punitivo calcado no encarceramento, o qual já deu suficientes mostras de completa falência, mas sim a importância da responsabilização das condutas violadoras, especialmente quando estamos tratando daqueles que são tidos como os piores e mais graves crimes praticados, crimes que são orquestrados a partir da estrutura estatal e cometidos pelos seus agentes, cuja compreensão desafia os padrões individuais da culpabilidade com os quais o Direito Penal tradicional está habituado ${ }^{12}$.

Assumindo um contexto sócio-jurídico muito distante da concretização de uma sociedade sem penas, e sem punições encarceradoras inclusive, tem-se que a possibilidade da responsabilização criminal desses crimes deve ser projetada não a partir de alguma racionalidade ou justificativa da pena em si, mas sim a partir da sua função de contenção do próprio sistema punitivo, o qual em situações de violação massiva opera de modo descontrolado, como já frisou Zaffaroni ${ }^{13}$.

De todo modo, como acima assinalado, o espectro de ações, medidas e reflexões abrangidos pelo campo da Justiça de Transição ultrapassa o tema da persecução penal. Nessa chave, as medidas transicionais apontam para possibilidades não taxativas ou exaustivas que operam para além de um momento de transição política, transcendem o caráter transitório e se alojam de modo perene na constante construção de uma sociedade menos violenta e mais democrática ${ }^{14}$. Trata-se ademais de uma temática que mobiliza diversas

\footnotetext{
${ }^{10}$ Ver em especial o Dossiê Crimes do Estado e Justiça de Transição, publicado no Vol. 2, n. 1, 2010.

${ }^{11}$ Foi para o que apontou Roberto Lyra Filho ao definir o direito como "a legítima organização social da liberdade" (LYRA FILHO, Roberto. O que é Direito. 12. ed. São Paulo: Brasiliense, 1991. p. 86).

${ }^{12}$ Sobre o tema ver especialmente: ZAFFARONI, Eugenio Raúl. La palabra de los muertos - conferencias de criminologia cautelar. Buenos Aires: Ediar, 2011. p. 419-499 (18ª a 20ª Conferencias); LORENZETTI, Ricardo Luis; KRAUT, Alfredo jorge. Derechos humanos: justicia y reparación - la experiencia de los juicios en la Argentina - Crímenes de lesa humanidad. Buenos Aires: Sudamericana, 2011.

${ }^{13}$ ZAFFARONI, Eugenio Raúl. Crímenes de Masa. Buenos Aires: Madres de Plaza de Mayo, 2010.

${ }^{14}$ Para um amplo panorama do campo de estudos da Justiça de Transição, tendo em vista mais diretamente o âmbito brasileiro e latino-americano ver, entre outros: SILVA FILHO, José Carlos Moreira da. Justica de Transição - da ditadura civil-militar ao debate justransicional - direito à memória e à verdade e os caminhos da reparação e da anistia no Brasil. Porto Alegre: Livraria do Advogado, 2015; SOUSA JUNIOR, José Geraldo de; SILVA FILHO, José Carlos Moreira da; RAMPIN, Talita; GIMENEZ, Lívia Fonseca; PAIXÃO, Cristiano. Introdução Crítica à Justiça de Transição na América Latina - série o Direito Achado na Rua vol.7. Brasília: UnB; Ministério da Justiça, 2015. SILVA FILHO, José Carlos Moreira da; ABRÃO, Paulo; TORELLY, Marcelo D. (orgs). Justiça de Transição nas Américas - olhares interdisciplinares, fundamentos e padrões de efetivação. Belo Horizonte: Fórum, 2013; TORELLY, Marcelo D. Justiça de Transição e Estado Constitucional de Direito - perspectiva teórico-comparativa e análise do caso brasileiro. Belo Horizonte: Fórum, 2012.
} 
disciplinas, como a História, a Filosofia, a Sociologia, a Ciência Política, o Direito, as Relações Internacionais, as Letras, a Psicanálise, a Antropologia, entre outros campos do saber. É, pois, tanto em função do caráter interdisciplinar e transdisciplinar quanto do seu foco na prevenção da violência, que se trata de um campo de estudos perfeitamente acolhido no âmbito do Programa de Pós-Graduação em Ciências Criminais da PUCRS, figurando explicitamente entre as linhas de pesquisa do Programa e já tendo conduzido a orientação e elaboração de monografias, teses e dissertações de grande qualidade.

Uma boa leitura a todos!

José CARLOS MoReira DA SILVA FILHO

Editor da revista Sistema Penal \& Violência. Professor no Programa de Pós-Graduação em Ciências Criminais e na Graduação em Direito da PUCRS. Vice-Presidente da Comissão de Anistia do Ministério da Justiça. 